\title{
E Tudo o Fogo Queimou: Vivências dos Médicos de Família Após o Grande Incêndio de 15 de Outubro de 2017
}

\author{
Gone with the Fire: How Family Physicians in Central \\ Portugal Experienced the Aftermath of the Great Fire of \\ October 15, 2017
}

Ana Sofia CARVALHO ${ }^{1}$, Sara MARQUES ${ }^{1,2}$, Frederico ROSÁRIO $\rrbracket^{1,3}$

Acta Med Port 2018 Jan;31(1):7-8 - https://doi.org/10.20344/amp.10178

Palavras-chave: Desastres; Fogo; Médicos de Família; Portugal; Transtornos de Stress Pós-Traumáticos

Keywords: Disasters; Fires; Physicians, Family; Portugal; Stress Disorders, Post-Traumatic

O domínio do fogo pelo ser humano remonta à préhistória. Esta conquista moldou de forma indelével a evolução da espécie, estando na base de diversos avanços tecnológicos e ganhos em saúde. A utilização do fogo para cozinhar os alimentos permitiu-nos não só experimentar novos sabores, mas também eliminar, pela ação do calor, diversos agentes patogénicos. O domínio do fogo está também associado a alguns dos capítulos mais negros da história humana. Nos séculos $X V$ e seguintes, milhares de mulheres foram mortas pela Inquisição em fogueiras, acusadas de bruxaria à luz do infame Malleus Maleficarum. Relatos do seu uso enquanto arma térmica podem, por exemplo, ser encontrados nos anais da guerra do Vietname com o uso de napalm.

O poder destrutivo do fogo tem ultimamente sido notícia pelos dantescos incêndios florestais a que repetidamente temos assistido. Só no continente europeu estima-se que deflagrem anualmente cerca de 70000 incêndios, com particular incidência nos países da bacia do Mediterrâneo. ${ }^{1}$ A Agência Europeia do Ambiente destaca Portugal como o país com maior número de ignições no período compreendido entre 1980 e 2013. ${ }^{1}$ Entre 1 de janeiro e 31 de outubro de 2017, o Sistema de Gestão de Informação de Incêndios Florestais contabilizou 16981 ignições $^{2}$ que consumiram 442418 hectares de floresta e vitimaram mais de 100 pessoas. $^{3}$

A 16 de outubro de 2017, o distrito de Viseu despertou para um cenário aterrador de floresta queimada, casas ardidas, pessoas feridas e vidas perdidas. Os mais de 400 incêndios que lavraram no norte e centro do país devastaram os concelhos de Tondela, Vouzela, Santa Comba Dão, Carregal do Sal, Oliveira de Frades, Nelas e Mortágua. Nessa manhã, no trajeto entre Viseu e Tondela, a caminho do centro de saúde, ardia ainda nas bermas o que restava da floresta. Da área ardida subiam inúmeras colunas de fumo. Os carros estavam cobertos por uma espessa camada de cinza caída de uma densa névoa cinzenta que cobria todo o céu. $O$ ar estava impregnado de um intenso - quase irrespirável - cheiro a fumo.

No Centro de Saúde de Tondela, uma multidão preenchia a sala de espera. Filas intermináveis ocuparam todo o dia a entrada do centro de saúde, aguardando a sua vez pelo atendimento administrativo. A gestão da agenda de consultas nesse, e nos dias que se seguiram à tragédia, foi um teste à capacidade de organização e à resiliência de todos os profissionais. Apoiar um utente após tal evento traumático é uma tarefa que consome um tempo indefinido, multiplicado por um número incerto de utentes que precisa desse apoio, sobreposto a uma agenda sobrecarregada de consultas com hora marcada. E como se não bastasse, a esta hercúlea tarefa juntaram-se as falhas na eletricidade, no abastecimento de água e no sistema informático, o blackout das comunicações telefónicas, os cortes de estradas que impossibilitaram diversos profissionais de comparecer nos seus locais de trabalho, e o acréscimo de trabalho burocrático de reportar semanalmente todas as consultas e referenciações realizadas relacionadas com os incêndios. É evidente a necessidade de melhorar a resistência das infraestruturas a estes eventos sob pena de, por falta de meios, não se poder dar resposta adequada às necessidades das populações. É também importante reforçar o trabalho multidisciplinar em rede se queremos minorar o impacto dos incêndios na saúde e na qualidade de vida, ${ }^{4}$ que passa pelo envolvimento e articulação entre entidades civis, públicas e privadas, pela centralização da informação e pelo desenvolvimento de um plano de atuação e acompanhamento estratégico. Esta não é uma realidade utópica. Em algumas regiões do Centro do país foram organizadas unidades de Saúde Mental comunitárias, que se propuseram cumprir estas premissas, e que mantêm a sua atuação nos locais afetados.

Ainda mais difícil que a gestão 'burocrática' das consultas foi a gestão emocional de, repetidamente, nos dias que se seguiram, ouvir os utentes contar na primeira

1. Unidade de Cuidados de Saúde Personalizados Tomaz Ribeiro. Tondela. Portugal.

2. Equipa Projeto em Cuidados Paliativos. Agrupamento de Centros de Saúde Dão Lafões. Viseu. Portugal.

3. Equipa Projeto Piloto em Problemas Ligados ao Álcool. Agrupamento de Centros de Saúde Dão Lafões. Viseu. Portugal.

$\triangle$ Autor correspondente: Frederico Rosário. fredmbr@gmail.com

Recebido: 03 de janeiro de 2018 - Aceite: 05 de janeiro de 2018 | Copyright @ Ordem dos Médicos 2018 
pessoa as suas histórias. É muito difícil, se não impossível, passar para o papel o que se sente ao contactar com as vítimas dos incêndios, mas talvez se consiga ter uma ideia se às frases que se seguem associarmos a imagem de utentes com o cabelo desalinhado, olhos encovados e marejados de lágrimas, faces aqui e ali ainda com vestígios de fuligem, e com as mesmas roupas com que enfrentaram o incêndio, entranhadas por um intenso odor a fumo: "Estávamos a fugir no carro, sem ver nada, sob um telhado de fogo, sem saber por onde ir, sem saber dos familiares."; "Só tivemos tempo de pegar na bebé e sair de casa em pijama."; "Doutor, perdi tudo... A casa ardeu, os animais morreram todos."; "Fiquei sem nada... apenas a roupa que tenho no corpo."; "Estamos todos vivos, mas não somos as mesmas pessoas."; "Já não vou conseguir restabelecer a minha vida... já não tenho idade."; "Cada vez que peço ao pequeno para se vestir mais rápido ele pergunta-me: Mamã, há outra vez fogo?". Dificilmente alguém se poderá considerar preparado para tal embate emocional. Invade-nos uma sensação de impotência, e o que no imediato podemos fazer é ouvir sem julgar, mostrar disponibilidade para ouvir novamente, respeitar o luto, e estar atento a sinais de alarme que impliquem outro tipo de apoio especializado (que podem só surgir anos mais $\operatorname{tarde}^{5}$ ).

As consequências do incêndio não se esgotam no desespero de quem tudo perdeu. São muitos os efeitos deletérios na saúde que podem ser provocados pelos incêndios. ${ }^{6}$ As queimaduras são porventura a face mais conhecida, e foram várias as pessoas que se deslocaram nos dias seguintes ao centro de saúde para realizar tratamentos de enfermagem. Problemas respiratórios, cardiovasculares e oftalmológicos podem resultar do contacto com o fumo, e está provado o aumento de doenças do foro psiquiátrico nas vítimas de incêndios ${ }^{5,6}$ Estar alerta para todas as situações que possam advir da vivência desta experiência traumática implica que os Médicos de Família possuam formação específica para o efeito. No entanto, a formação nesta área é escassa ou inexistente para a maioria dos profissionais de saúde, em alguns casos mesmo nos que trabalham em serviços de emergência. ${ }^{7}$ Ainda que se advoguem (e bem!) medidas para a prevenção dos incêndios, a verdade é que as catástrofes continuarão a acontecer no futuro, pelo que será importante pensar em que medida a formação nesta área pode ser incluída na formação médica.

O fogo queimou tudo. Um manto de cinza escurecerá para sempre a alma dos que the sobreviveram. O grande incêndio de 15 de outubro de 2017, e as semanas que a ele se seguiram, vieram pôr a descoberto as dificuldades que os Médicos de Família sentem para gerir o tremendo desafio de apoiar as populações no pós-incêndio: faltanos formação específica; não dispomos de um plano articulado de trabalho em rede; as infraestruturas que dão suporte à nossa atividade são deficitárias. As crises são oportunidades de mudança e as dificuldades estão à vista - vamos todos continuar a assobiar para o lado?

\section{REFERÊNCIAS}

1. Forest fires. European Environment Agency [Internet]. 2017. [consultado 2017 dez 28]. Disponível em https://www.eea.europa.eu/data-andmaps/indicators/forest-fire-danger-2/assessment.

2. Instituto da Conservação da Natureza e das Florestas. Departamento de Gestão de Áreas Públicas e de Proteção Florestal. Relatório Provisório de Incêndios Florestais - 2017- 01 Janeiro a 31 Outubro de 2017. Número: RIF10/2017. 2017. [consultado 2017 dez 22]. Disponível em http://www2.icnf.pt/portal/florestas/dfci/Resource/doc/rel/2017/10rel-prov-1jan-31out-2017.pdf.

3. Agência Lusa (2017, 04 de Dezembro). Mais de 100 mortos no pior ano de fogos em Portugal. Diário de Notícias. [consultado 2018 jan 1]. Disponível em http://www.dnoticias.pt/pais/mais-de-100-mortos-nopior-ano-de-fogos-em-portugal-ND2445528.

4. Incêndios: profissionais defendem trabalho em rede e multidisciplinar.

Alert [Internet]. 2017 [consultado 2017 dez 29]. Disponível em http:// www.alert-online.com/pt/news/health-portal/incendios-profissionaisdefendem-trabalho-em-rede-e-multidisciplinar.

5. Finlay SE, Moffat A, Gazzard R, Baker D, Murray V. Health impacts of wildfires. Version 1. PLoS Curr. 2012;2;4:e4f959951cce2c.

6. Freedy JR, Simpson WM. Disaster-related physical and mental health: a role for the family physician. Am Fam Physician. 2007;15:841-6.

7. Hauke A, Georgiadou P, Pinotsi D, Kallio H, Lusa S, Malmelin J, et al. Emergency services: a literature review on occupational safety and health risks. European Agency for Safety and Health at Work. 2011. [consultado 2017 dez 29]. Disponível em https://osha.europa.eu/en/ tools-and-publications/publications/literature_reviews/emergency services_occupational_safety_and_health_risks 